\title{
Antidepressant use and risk of adverse outcomes in older people: population based cohort study
}

\author{
Carol Coupland associate professor in medical statistics ${ }^{1}$, Paula Dhiman research statistician ${ }^{1}$, \\ Richard Morriss professor of psychiatry and community mental health ${ }^{2}$, Antony Arthur associate \\ professor in elder care ${ }^{3}$, Garry Barton senior lecturer in health economics ${ }^{4}$, Julia Hippisley-Cox \\ professor of clinical epidemiology and general practice ${ }^{1}$
}

${ }^{1}$ Division of Primary Care, University of Nottingham, Nottingham NG7 2RD, UK; ${ }^{2}$ Division of Psychiatry, University of Nottingham; ${ }^{3}$ Division of Nursing, University of Nottingham; ${ }^{4}$ Health Economics Group (HEG), School of Medicine, Health Policy and Practice, University of East Anglia, Norwich, UK

\begin{abstract}
Objectives To investigate the association between antidepressant treatment and risk of several potential adverse outcomes in older people with depression and to examine risks by class of antidepressant, duration of use, and dose.

Design Cohort study of people aged 65 and over diagnosed as having depression.

Setting 570 general practices in the United Kingdom supplying data to the QResearch primary care database.

Participants 60746 patients diagnosed as having a new episode of depression between the ages of 65 and 100 years from 1 January 1996 to 31 December 2007 and followed up until 31 December 2008.

Main outcome measures Hazard ratios associated with antidepressant use for all cause mortality, attempted suicide/self harm, myocardial infarction, stroke/transient ischaemic attack, falls, fractures, upper gastrointestinal bleeding, epilepsy/seizures, road traffic accidents, adverse drug reactions, and hyponatraemia, adjusted for a range of potential confounding variables. Hazard ratios were calculated for antidepressant class (tricyclic and related antidepressants, selective serotonin reuptake inhibitors, other antidepressants), dose, and duration of use and for commonly prescribed individual drugs.

Results 54038 (89.0\%) patients received at least one prescription for an antidepressant during follow-up. A total of 1398359 antidepressant prescriptions were issued: $764659(54.7 \%)$ for selective serotonin reuptake inhibitors, $442192(31.6 \%)$ for tricyclic antidepressants, 2203 $(0.2 \%)$ for monoamine oxidase inhibitors, and 189305 (13.5\%) for the group of other antidepressants. The associations with the adverse outcomes differed significantly between the antidepressant classes for seven outcomes. Selective serotonin reuptake inhibitors were associated with the highest adjusted hazard ratios for falls (1.66, 95\% confidence interval 1.58 to 1.73 ) and hyponatraemia $(1.52,1.33$ to 1.75$)$ compared with when antidepressants were not being used. The group of other
\end{abstract}

antidepressants was associated with the highest adjusted hazard ratios for all cause mortality (1.66, 1.56 to 1.77$)$, attempted suicide/self harm $(5.16,3.90$ to 6.83$)$, stroke/transient ischaemic attack $(1.37,1.22$ to $1.55)$, fracture $(1.64,1.46$ to 1.84$)$, and epilepsy/seizures $(2.24,1.60$ to $3.15)$, compared with when antidepressants were not being used. Tricyclic antidepressants did not have the highest hazard ratio for any of the outcomes. Significantly different associations also existed between the individual drugs for the same seven outcomes; trazodone (tricyclic antidepressant), mirtazapine, and venlafaxine (both in the group of other antidepressants) were associated with the highest rates for some of these outcomes. Absolute risks over 1 year for all cause mortality were $7.04 \%$ for patients while not taking antidepressants, $8.12 \%$ for those taking tricyclic antidepressants, $10.61 \%$ for selective serotonin reuptake inhibitors, and $11.43 \%$ for other antidepressants.

Conclusions Selective serotonin reuptake inhibitors and drugs in the group of other antidepressants were associated with an increased risk of several adverse outcomes compared with tricyclic antidepressants. Among individual drugs, trazodone, mirtazapine, and venlafaxine were associated with the highest risks for some outcomes. As this is an observational study, it is susceptible to confounding by indication, channelling bias, and residual confounding, so differences in characteristics between patients prescribed different antidepressant drugs that could account for some of the associations between the drugs and the adverse outcomes may remain. Further research is needed to confirm these findings, but the risks and benefits of different antidepressants should be carefully evaluated when these drugs are prescribed to older people.

\section{Introduction}

Depression is a common condition in older people, affecting around $10-15 \%$ of those living in the community. ${ }^{12}$ In the United Kingdom, depression is largely treated in primary care with antidepressant drugs. Antidepressants are one of the most 
commonly prescribed drug groups in primary care. Around 39 million prescriptions for antidepressants were issued in the community in England in 2009 across all ages, an increase of $35 \%$ over five years. ${ }^{3}$ Prescriptions increased most for the class of selective serotonin reuptake inhibitor antidepressants-a $47 \%$ increase over five years, compared with an $18 \%$ increase for the class of tricyclic and related antidepressants and a $37 \%$ increase for other antidepressants. ${ }^{45} \mathrm{~A}$ systematic review in older people found that tricyclic antidepressants and selective serotonin reuptake inhibitors were equivalent in terms of efficacy but that classic tricyclic antidepressants were associated with a higher discontinuation rate owing to side effects. ${ }^{6}$ The National Institute for Health and Clinical Excellence recommends that the choice of an antidepressant should be guided by consideration of side effects and the patient's preferences but that normally a selective serotonin reuptake inhibitor in generic form should be chosen.

Little is known about more serious adverse effects of antidepressants, particularly in older people, in whom adverse drug events may be more common in the treatment of depression compared with younger groups because of higher levels of comorbidity, age related physiological changes, and polypharmacy. ${ }^{8}$ The under-representation of older people in clinical trials of antidepressants and the fact that most such trials are short term make deriving reliable or precise estimates of the incidence of adverse events in this group difficult. ${ }^{9}{ }^{10}$ This problem is further compounded when criteria for trials exclude older people with comorbid conditions. ${ }^{11}$ Although several observational studies have examined different adverse outcomes associated with use of antidepressants, ${ }^{12}$ few have been specific to an older population.

We therefore did a large cohort study of antidepressant use in older people to investigate the association between antidepressant treatment and risk of several potential adverse outcomes. We directly compared antidepressant class effects and examined dose and associations with use of commonly prescribed individual drugs. We aimed to derive a comprehensive and integrated picture of the relative safety and balance of risks for antidepressant drugs in older people diagnosed as having depression.

\section{Methods}

Full details of the study methods are published in a Health Technology Assessment monograph. ${ }^{13}$ We report the key findings of the study here, and further results are presented in the full report.

\section{Setting}

In summary, we used the QResearch primary care research database (version 22) to do a cohort study in a large population of primary care patients. Practices that provide data for QResearch use the Egton Medical Information Systems (EMIS) medical records system. EMIS is the major supplier of primary care computer systems in the UK and is in use in around two thirds of UK general practices. The practices that contribute data to QResearch are spread throughout the UK and comprise around 7\% of all UK general practices. A comparison of QResearch practices with all UK practices found that practices contributing to QResearch tended to be marginally larger than UK practices overall but were similar in other respects. ${ }^{14}$ The database includes data on patients' demographics, consultations, symptoms, diagnoses (including diagnoses made in secondary care obtained from hospital discharge letters), referrals, results of investigations, and prescribed drugs.

\section{Study cohort}

The target population for the cohort study was all patients in the QResearch database with a recorded diagnosis of depression made when they were aged 65 and over and between 1 January 1996 and 31 December 2007. We used the first such diagnosis as the index diagnosis. We used computer recorded Read codes to identify a diagnosis of depression, using case definitions similar to those that have been used in previous studies. ${ }^{15} 16$ Patients with a previous recorded diagnosis of depression before the age of 65 were eligible for inclusion in the study to increase the representativeness of the study cohort. We excluded patients if any of the following applied: they were aged 100 years or more at diagnosis; the diagnosis occurred less than 12 months after registration with a study practice or after the installation date of the practice's EMIS computer system; they were temporary residents; they had a diagnosis of depression in the 12 months before their index recorded diagnosis of depression; they had been prescribed antidepressants in the 12 months before their recorded diagnosis of depression; or they had a diagnosis of schizophrenia, bipolar disorder, or other types of psychoses. We defined the date of entry in the study for each patient as the date of the first recorded diagnosis of depression after age 65 within the study period or the date of the first prescription for an antidepressant after age 65 if that occurred before the recorded date of depression.

\section{Outcome data}

We followed the cohort until 31 December 2008. We extracted information on adverse outcomes during follow-up from the primary care computer records on the basis of computer recorded Read codes (which include diagnoses made in primary and secondary care) and also from the linked death certificates by using ICD-9 (international classification of diseases, 9th revision) and ICD-10 codes if patients had died during the follow-up period. We included outcomes only if they occurred after the study entry date and up to 31 December 2008. The pre-specified outcomes were all cause mortality, attempted suicide/self harm, myocardial infarction, stroke/transient ischaemic attack, falls, fractures (upper limb, lower limb, ribs, skull, vertebrae, pelvis), upper gastrointestinal bleeding, epilepsy/seizures, road traffic accidents, adverse drug reactions (including bullous eruption), and hyponatraemia.

Three other pre-specified outcomes were sudden cardiac death, suicide (including open verdicts), and overdose/poisoning from antidepressants, but the numbers of patients identified with these outcomes were small, which limited the analyses that could be done. We did an additional analysis using stroke as an outcome, excluding transient ischaemic attacks.

\section{Exposure data}

The primary exposure of interest was treatment with antidepressant drugs. We extracted information on all individual prescriptions for antidepressants during follow-up, including detailed information on the drug name and formulation, dosage instructions, and numbers of tablets issued for each prescription. We grouped antidepressant drugs for analysis according to the major classes of antidepressants as described in the British National Formulary ${ }^{17}$ : tricyclic and related antidepressants, monoamine oxidase inhibitors, selective serotonin reuptake inhibitors, and other antidepressants.

Some patients received prescriptions for different drugs within a class or drugs from different classes on the same date. We classified these prescriptions as combined prescriptions for some analyses (results not presented but available from the authors). 
We determined the duration of each prescription in days by dividing the number of tablets prescribed by the dosing directions (for example, number of tablets to be taken each day). To calculate the daily dose of each prescription, we multiplied the specified dose of each tablet prescribed by the number of tablets to be taken each day, where this could be evaluated. To enable comparison of doses between the antidepressant classes, we converted daily dose to a defined daily dose, by using values assigned by the World Health Organization's Collaborating Centre for Drug Statistics Methodology (www.whocc.no/atc_ ddd_index).

\section{Confounding variables}

The potential confounding variables included in the analysis were age at study entry date; sex (male, female); year of diagnosis of depression; previous recorded diagnosis of depression before age 65 ; severity of index diagnosis of depression (categorised as mild, moderate, or severe on the basis of the Read code for the index diagnosis, using codes for each category published by Martinez and colleagues ${ }^{16}$ and some classification by a member of the study team (RM) for Read codes for depression not included in the published list; the Read codes and their severity categorisation are given in the web appendix); deprivation, based on Townsend deprivation score for the patient's postcode, ${ }^{18}$ categorised into fifths according to the overall QResearch population; smoking status (non-smoker, ex-smoker, current smoker); comorbidities at baseline (coronary heart disease, diabetes, hypertension, stroke/transient ischaemic attack, cancer, dementia, epilepsy/seizures, Parkinson's disease, hypothyroidism, obsessive-compulsive disorder, identified by using appropriate computer recorded Read codes in the patients' records); use of other drugs at baseline (statins, non-steroidal anti-inflammatory drugs, antipsychotics, lithium, aspirin, antihypertensive drugs, anticonvulsants, hypnotics/anxiolytics); and previous falls before baseline (for the analysis of fracture).

\section{Statistical analysis}

We used Cox's proportion hazards models to do separate analyses for each outcome. We used time to the first recorded diagnosis of each outcome in the analyses and excluded patients who already had the outcome recorded at baseline. We censored patients who did not have the outcome of interest during follow-up at the earliest of date of death, date of leaving the practice, date of the latest download of data, or the study end date (31 December 2008). We treated antidepressant use as a time varying exposure to account for patients stopping treatment and changing between treatments during follow-up. For the main analyses, we considered patients to be exposed to treatment if no gaps of more than 90 days existed between the end of one prescription and the start of the next.

The analysis calculated hazard ratios and $95 \%$ confidence intervals for antidepressant treatment, both unadjusted and adjusted for the potential confounding variables described above, excluding patients with missing values for smoking status or deprivation. The main analyses examined use of each class of antidepressants (selective serotonin reuptake inhibitors, tricyclic antidepressants, and other antidepressants) compared with no current treatment and also directly compared selective serotonin reuptake inhibitors and the group of other antidepressants with tricyclic antidepressants. We did analyses for antidepressant dose, categorising dose for each antidepressant class into three categories ( $\leq 0.5$ defined daily doses, $>0.5$ and $\leq 1.0$ defined daily doses, and $>1.0$ defined daily doses). We did tests of trend using continuous dose in defined daily doses for each class. We examined duration of treatment as a time varying exposure based on time since starting antidepressant treatment and time since stopping treatment categorised for each antidepressant class as no use, 1-28 days' use, 29-84 days' use, and 85 or more days' use and periods of 1-28 days, 29-84 days, and 85-182 days after stopping treatment. We compared use of individual antidepressant drugs with no current treatment when numbers were sufficient. We excluded patients who had taken monoamine oxidase inhibitors at any time during follow-up from these analyses, as numbers were too small to allow precise estimates to be made.

We used a $P$ value of $<0.01$ (two tailed) to assess statistical significance. We did Wald's significance tests to determine whether the categorical variable for antidepressant class was significant overall and to test for equality of effects of the different classes, excluding the category of no current treatment, to determine whether significant differences existed between the classes. We also did this for the analyses of individual drugs. We assessed whether the assumption of proportional hazards was valid graphically. We used Stata (v10.1) for all analyses.

We estimated absolute risks for each outcome at one year from the index date, firstly in patients while they were not taking antidepressant treatment and then combining this with the adjusted hazard ratios for antidepressant class and individual drugs to calculate adjusted absolute risks in the treated groups by using a published formula. ${ }^{19}$ We included all eligible patients in the database in our analyses to maximise power.

\section{Results}

A total of 88701 patients in the QResearch database had a recorded diagnosis of depression made at the age of 65 and over between 1 January 1996 and 31 December 2007. After we consecutively excluded 22 patients aged 100 and over at diagnosis, 3178 patients with schizophrenia, bipolar disorder, or other psychoses, 15690 who had joined the practice in the previous year, and 9065 with a diagnosis of depression or a prescription for an antidepressant in the previous year, 60746 eligible patients remained. These patients were from 570 QResearch practices, including 543 in England, 14 in Wales, four in Scotland, and nine in Northern Ireland.

Table 1 shows baseline characteristics of the study cohort. The mean age of the study cohort was 75.0 years, and the cohort contained $20230(33.3 \%)$ men and $40516(66.7 \%)$ women. The total number of person years of follow-up was 305188 , with a mean of 5.0 (SD 3.3) years per patient.

\section{Patterns of antidepressant treatment}

During follow-up, 54038 (89.0\%) patients received at least one prescription for an antidepressant drug, and a total of 1398359 prescriptions for antidepressants were issued. A total of 6484 (10.7\% of 60746 ) patients had only a single prescription for an antidepressant, and $6624(10.9 \%)$ received 60 prescriptions or more during follow-up. The median duration of treatment with antidepressants during follow-up was 364 (interquartile range 91-1029) days.

Selective serotonin reuptake inhibitors were the most commonly prescribed drug class, comprising 54.7\% (764 659) of the total antidepressant prescriptions. Patients received 442192 (31.6\% of all antidepressant prescriptions) prescriptions for tricyclic antidepressants and 189305 (13.5\%) for the group of other antidepressants. Monoamine oxidase inhibitor drugs were the least commonly prescribed class, comprising only $0.2 \%$ (2203 prescriptions) of the total prescriptions issued. Because of the small number of prescriptions for monoamine oxidase inhibitors, 
we excluded patients prescribed these drugs from further analysis. Table 2 shows the prescribed doses by antidepressant class for the prescriptions where this could be evaluated. Doses tended to be lowest for tricyclic antidepressants $-70.0 \%$ of prescriptions were for $\leq 0.5$ defined daily doses, compared with $13.8 \%$ for selective serotonin reuptake inhibitors and $19.2 \%$ for the group of other antidepressants.

The 10 most commonly prescribed antidepressant drugs (citalopram hydrobromide (selective serotonin reuptake inhibitor), fluoxetine hydrochloride (selective serotonin reuptake inhibitor), amitriptyline hydrochloride (tricyclic antidepressant), dosulepin hydrochloride (tricyclic antidepressant), paroxetine hydrochloride (selective serotonin reuptake inhibitor), venlafaxine hydrochloride (other), sertraline hydrochloride (selective serotonin reuptake inhibitor), mirtazapine (other), lofepramine (tricyclic antidepressant), and escitalopram (selective serotonin reuptake inhibitor)) comprised 93.6\% ( $\mathrm{n}=1$ 309 056) of all antidepressant prescriptions. As only slightly fewer prescriptions for trazodone hydrochloride (tricyclic antidepressant) were issued, we considered the 11 most commonly prescribed drugs, comprising $96.0 \%$ ( $n=1342731$ ) of all prescriptions, separately in some analyses (fig 1).

\section{Results of analyses by antidepressant class}

Tables 3 and 4 show the results of the analysis by antidepressant class. All classes of antidepressant drug were associated with significantly increased risks of all cause mortality, attempted suicide/self harm, falls, fractures, and upper gastrointestinal bleeding compared with when these drugs were not being used. Selective serotonin reuptake inhibitors and the group of other antidepressant drugs were associated with increased risks of stroke/transient ischaemic attack and epilepsy/seizures; selective serotonin reuptake inhibitors were also associated with increased risks of myocardial infarction and hyponatraemia.

The associations with the adverse outcomes differed significantly between the classes of antidepressant drugs for seven outcomes: all cause mortality, attempted suicide/self harm, stroke/transient ischaemic attack, falls, fracture,

epilepsy/seizures, and hyponatraemia. For these outcomes, when compared directly with tricyclic antidepressants, selective serotonin reuptake inhibitors were associated with significantly higher rates of all cause mortality (adjusted hazard ratio 1.32, 95\% confidence interval 1.26 to 1.39 ), stroke/transient ischaemic attack $(1.15,1.05$ to 1.26$)$, falls $(1.27,1.20$ to 1.35$)$, fracture (1.26, 1.15 to 1.37$)$, epilepsy/seizures (1.80, 1.32 to 2.43$)$, and hyponatraemia (1.44, 1.19 to 1.75$)$. We found no significant difference for attempted suicide/self harm (1.27, 0.97 to 1.66).

The group of other antidepressants had significantly higher rates compared with tricyclic antidepressants for all cause mortality (adjusted hazard ratio 1.43, 1.33 to 1.54), attempted suicide/self harm $(3.04,2.21$ to 4.17$)$, stroke/transient ischaemic attack $(1.35,1.18$ to 1.54$)$, fracture $(1.31,1.15$ to 1.50$)$, and epilepsy/seizures $(2.20,1.46$ to 3.30$)$. We found no significant difference for falls $(1.07,0.97$ to 1.17$)$ or hyponatraemia $(1.21$, 0.90 to 1.64). Tricyclic antidepressants were not associated with significantly higher rates of any of the outcomes when compared with selective serotonin reuptake inhibitors or the group of other antidepressants.

We found similar results in an additional analysis that included only strokes as an outcome rather than strokes and transient ischaemic attacks. For example, the adjusted hazard ratio was 1.05 (0.95 to 1.17) for tricyclic antidepressants, 1.21 (1.11 to 1.32) for selective serotonin reuptake inhibitors, and 1.44 (1.24 to 1.67) for other antidepressants, all compared with when antidepressants were not being used.

The proportional hazards assumption of the Cox proportional hazards model was reasonable for most outcomes, although we found some indication of convergence for stroke/transient ischaemic attack, upper gastrointestinal bleeding, and hyponatraemia towards the end of the follow-up period.

\section{Results of analyses for individual antidepressant drugs}

Figure 2 shows adjusted hazard ratios associated with the 11 most commonly prescribed individual drugs. We found significant differences between the associations with these drugs $(\mathrm{P}<0.01)$ for all cause mortality, attempted suicide/self harm, stroke/transient ischaemic attack, falls, fracture, epilepsy/seizures, and hyponatraemia.

Trazodone (a tricyclic antidepressant) was associated with the highest adjusted hazard ratio for all cause mortality and one of the highest hazard ratios for attempted suicide/self harm. Mirtazapine (in the group of other antidepressants) was associated with the highest adjusted hazard ratio for attempted suicide/self harm and one of the highest for all cause mortality and stroke/transient ischaemic attack. Venlafaxine (in the group of other antidepressants) was associated with higher adjusted hazard ratios for stroke/transient ischaemic attack, fracture, and epilepsy/seizures than the other drugs and with one of the highest for all cause mortality and attempted suicide/self harm. Citalopram (a selective serotonin reuptake inhibitor) was associated with the highest adjusted hazard ratio for falls, but risks were similar for all of the selective serotonin reuptake inhibitors.

Three selective serotonin reuptake inhibitors (citalopram, escitalopram, and fluoxetine) were associated with significantly increased risks of hyponatraemia, but paroxetine and sertraline were not. We found some evidence of increased rates of adverse drug reactions associated with lofepramine and sertraline. Amitriptyline and dosulepin (both tricyclic antidepressants) had the lowest risks for many of these outcomes.

We found similar results in an additional analysis that only included strokes as an outcome rather than strokes and transient ischaemic attack, except for a higher hazard ratio associated with trazodone (adjusted hazard ratio 1.48, 1.08 to 2.04) compared with when antidepressants were not being used.

\section{Analyses by dose and duration}

We found significant trends (at $\mathrm{P}<0.01$ ) with dose of tricyclic antidepressants and selective serotonin reuptake inhibitors for all cause mortality, falls, and epilepsy/seizures. We also found a significant dose-response relation between dose of tricyclic antidepressants and fracture (see web extra table A). For most outcomes, risks were highest in the first 28 days of use and also in the first 28 days after stopping antidepressant treatment (see web extra table B).

\section{Absolute risks}

Table 5 shows absolute risks at one year by antidepressant class and individual drug for each of the adverse outcomes. The absolute risks were highest for all cause mortality, stroke/transient ischaemic attack, falls, and fracture. Absolute risks for all cause mortality over one year were $7.04 \%$ for patients while not taking antidepressants, $8.12 \%$ for those taking tricyclic antidepressants, $10.61 \%$ for selective serotonin reuptake inhibitors, and $11.43 \%$ for other antidepressants. 


\section{Discussion}

This observational study found significant associations between use of antidepressant drugs and several severe adverse outcomes in people aged 65 and older with depression. We found no evidence that use of selective serotonin reuptake inhibitors or drugs in the group of other antidepressants were associated with a reduced risk of any of the adverse outcomes compared with tricyclic antidepressants. However, compared with tricyclic antidepressants, selective serotonin reuptake inhibitors may be associated with an increased risk of certain outcomes, including all cause mortality, stroke/transient ischaemic attack, falls, fracture, epilepsy/seizures, and hyponatraemia, and the group of other antidepressants may be associated with an increased risk of all cause mortality, attempted suicide/self harm, stroke/transient ischaemic attack, fracture, and epilepsy/seizures. Examination of individual drugs found that trazodone, mirtazapine, and venlafaxine were associated with the highest rates for some outcomes. To our knowledge, this is the first published systematic assessment of the safety of commonly used antidepressants in older patients across a range of serious adverse outcomes.

\section{Possible explanations for findings}

Tricyclic antidepressants were prescribed at lower doses than were selective serotonin reuptake inhibitors and other antidepressant drugs, which could in part explain our findings. However, within separate categories of dose, tricyclic antidepressants still tended to be associated with lower adjusted hazard ratios for all cause mortality, attempted suicide/self harm, stroke/transient ischaemic attack and epilepsy/seizures within each dose category. Also, this reflects prescribing patterns in primary care, and some evidence shows that low dose tricyclic antidepressants are similar to higher dose tricyclics in terms of reducing symptoms of depression. ${ }^{70}$

Rates of most outcomes were highest in the first 28 days after starting an antidepressant, and also in the first 28 days after stopping. For all cause mortality, myocardial infarction, stroke/transient ischaemic attack, adverse drug reactions, and hyponatraemia, we found some evidence that rates were reduced after 85 days of use. Changes in the severity of depression, particularly after starting antidepressant treatment, could explain why increases in rates of adverse events were generally most marked in the first 28 days after a prescription, when the depression is likely to be more severe, and could also explain the reductions in rates for some outcomes after 85 days of use when the depression may be resolving. This will have less effect on direct comparisons between antidepressant classes or individual drugs than on comparisons with non-use of antidepressants. The increased rates after stopping treatment may reflect patients stopping the drugs because of an onset of illness or after being admitted to hospital or a residential home, and increased rates of adverse events may be associated with these factors rather than being a direct effect of withdrawal.

\section{Strengths and limitations}

This was a large population based study with broad inclusion criteria, so the findings are generalisable to the population of older people diagnosed as having depression in primary care. This is in contrast with clinical trials, which generally have strict inclusion and exclusion criteria, tending to lead to the exclusion of many older people who have comorbidities or are taking drugs for other conditions. In addition, we included all eligible patients, which reduced selection bias. The study size enabled us to detect associations with relatively rare adverse events.
The data were recorded prospectively, so all information on prescriptions for antidepressants and potential confounding variables was recorded before the occurrence of an adverse outcome, meaning that recall bias will not have occurred. We adjusted our analyses for several potential confounding variables, including comorbidities and use of other drugs.

We had detailed information on prescriptions for antidepressants issued in primary care throughout the follow-up period, so we could do comprehensive analyses investigating effects of individual drugs, dose, and duration. This contrasts with many cohort or case-control studies in which information on antidepressant use is self reported or collected only at the start of the study.

The main concern with observational studies such as this one is indication bias. Indication bias occurs when patients are prescribed drugs for a condition that is itself associated with the outcome of interest. This means that apparent associations with a drug may be due to the condition for which it was prescribed rather than to the drug itself. To reduce this bias, we restricted our study cohort to include only patients with a recorded diagnosis of depression, so that all patients, whether treated or not, had the same indication for treatment. This is important, as depression itself is associated with many adverse outcomes. ${ }^{21-23}$ Some systematic differences are still likely between patients who are treated and those who are not. Those who are not treated are likely to have less severe depression and may have poorer physical health, such that they are considered too frail for antidepressant treatment. We adjusted for many factors that could differ between groups, including age, sex, severity of depression, several comorbidities, and use of other drugs. Generally, the adjustment did not have a large effect on the results. However, although we adjusted for severity of the initial diagnosis of depression, we could use only a crude measure as we did not have a validated depression severity score. We cannot therefore exclude the possible effect of residual confounding on our results.

Direct comparisons between treated groups are less susceptible to confounding by indication, or confounding due to factors influencing prescribing of treatment, but are still subject to channelling bias, whereby different antidepressant drugs with similar indications might be prescribed according to varying characteristics of patients. An example of this would be the preferential prescribing of selective serotonin reuptake inhibitors rather than tricyclic antidepressants to frail patients at greater risk of falling. ${ }^{24}$ Again, adjusting for a range of potential confounding factors would be expected to reduce the effect of this bias; for example, in the analysis of fracture we adjusted for falls at baseline as well as for many other confounders. This bias would also be less likely to apply to comparisons between individual drugs within a class than to comparisons between classes.

Residual confounding may remain in the findings, as certain potential confounding variables may not be recorded on the database or may not be recorded in sufficient detail to completely remove their confounding effect. As a supplementary analysis, we did a self controlled case series analysis. This is a within patients comparison, which implicitly removes the effects of all characteristics that vary between patients, irrespective of whether or in how much detail they have been recorded on the database, assuming that they do not vary over time within the observation period. ${ }^{25}$ The results from the case series analyses were generally consistent with the cohort analyses, although the risks for attempted suicide/self harm for the group of other antidepressants were lower. ${ }^{13}$ These analyses, however, are also susceptible to confounding from time varying factors. We 
cannot, therefore, exclude the possible effect of residual confounding for these results.

We did not specifically validate our outcomes as part of this study. However, reviews of validation studies in other UK primary care databases have shown overall high levels of validity, and we would expect similar levels of validity in QResearch. ${ }^{26}{ }^{27}$ For example, Khan reported that particularly high $(>90 \%)$ proportions of cases recorded in the general practice record were confirmed when further information was obtained for several outcomes including cerebrovascular disease, hip fracture, and upper gastrointestinal bleeding. ${ }^{27} \mathrm{We}$ included information from death certificates to identify additional patients with the outcomes, which will have reduced misclassification.

We have assessed only potential adverse effects of antidepressants in this study and not potential benefits, as very limited data are available for evaluating effectiveness of the different antidepressants in the QResearch database.

\section{Comparison with other studies}

Several observational studies have examined the effects of antidepressant drugs on single adverse outcomes, although few have been done specifically in older people or have examined them as a subgroup and few, if any, studies have directly compared adverse event rates across a range of important clinical outcomes. These studies have identified several adverse outcomes that may be associated with antidepressants, but an intrinsic problem with observational studies of antidepressants is the difficulty of distinguishing between the effects of antidepressant drugs and depression itself.

\section{Attempted suicide/self harm}

Relatively few studies have looked at antidepressants and attempted suicide/self harm in older people. A meta-analysis of randomised controlled trials registered with the US Food and Drug Administration found a reduced risk of suicidal behaviour and ideation associated with antidepressants in the group aged 65 years and over. ${ }^{28}$ It found no evidence of a difference between drug classes across people of all ages. A systematic review of observational studies also found a reduction in risk of suicide or attempted suicide associated with use of selective serotonin reuptake inhibitors in the subgroup aged 65 years and older. ${ }^{29}$ Little evidence supports or refutes our findings of increased rates associated with mirtazapine, venlafaxine, and trazodone compared with other antidepressants, and these warrant further investigation.

\section{Myocardial infarction and stroke}

The literature contains no clear findings for risk of myocardial infarction and antidepressant use in older people. Some studies have found an increased risk of myocardial infarction associated with antidepressant use,$^{30-33}$ some have found a protective effect, ${ }^{34-36}$ and others have found no association. ${ }^{37}$ An increased risk has been observed as being restricted to tricyclic antidepressants or selective serotonin reuptake inhibitors, ${ }^{32} 33$ applying across classes, ${ }^{30}{ }^{31}$ or restricted to particular drugs. ${ }^{15}$ Evidence of a protective effect is largely limited to selective serotonin reuptake inhibitors. ${ }^{34} 35$

Findings from previous studies of antidepressants and risk of stroke are inconsistent, but some studies have found (as we did) a possible increase in risk among users of selective serotonin reuptake inhibitors and the group of other antidepressants. ${ }^{37} 38$ If selective serotonin reuptake inhibitors have an effect on occurrence of stroke, this may result from an increased risk of bleeding complications, as these drugs limit uptake of blood serotonin by platelets, which leads to inhibition of platelet aggregation, thereby preventing haemostasis by platelets. ${ }^{39} 40$ This mechanism could explain an association specifically with haemorrhagic stroke, but we were not able to distinguish between ischaemic and haemorrhagic stroke in this study.

\section{Falls and fracture}

A review of 78 studies found that the effects of tricyclic antidepressants and selective serotonin reuptake inhibitors on the risk of falls were generally similar across studies; few data were available for other antidepressants. ${ }^{41}$ Two studies specifically in older patients found that selective serotonin reuptake inhibitors in particular were strongly associated with the risk of falls. ${ }^{42}{ }^{43}$ A cohort study of patients aged 60 and over found that selective serotonin reuptake inhibitors were associated with a more than twofold increase in the risk of falls but found no significant increase for other antidepressants. ${ }^{44}$ Findings from the literature suggest that selective serotonin reuptake inhibitors and tricyclic antidepressants are associated with increased fracture rates,${ }^{24} 45-47$ with possibly somewhat higher rates for selective serotonin reuptake inhibitors than for tricyclic antidepressants. ${ }^{45-47}$ Little evidence exists for other antidepressants. Our findings of a more marked and prolonged increase in risk for selective serotonin reuptake inhibitors compared with tricyclic antidepressants are in general agreement with this. The increased risk of fracture associated with antidepressant use may be due to an increased risk of falls, but some evidence also shows reduced bone mineral density in users of selective serotonin reuptake inhibitors. ${ }^{48} 49$

\section{Gastrointestinal bleeding}

Gastrointestinal bleeding has been found in some studies to be more common among patients taking selective serotonin reuptake inhibitors, ${ }^{50}{ }^{51}$ including those aged 65 years and over. ${ }^{52}$ A proposed mechanism for this finding is that these drugs block serotonin reuptake by platelets, leading to impairment of the platelet haemostatic response..$^{53} \mathrm{~A}$ study that adjusted for a wide range of potential confounding factors found a small increased risk of gastrointestinal bleeding among users of selective serotonin reuptake inhibitors, which is comparable in magnitude to ours, with no association for tricyclic antidepressants. ${ }^{54} \mathrm{We}$ found some evidence that venlafaxine is associated with a particularly increased risk of gastrointestinal bleeding, which has also been found in other studies. ${ }^{51}{ }^{54}$

\section{Hyponatraemia}

Hyponatraemia associated with antidepressant use is an adverse event that disproportionately affects older people. ${ }^{55}{ }^{56}$ Studies have shown that hyponatraemia is associated most strongly with use of selective serotonin reuptake inhibitors, ${ }^{56-58}$ and our findings are in accordance with that. In these studies, hyponatraemia developed within the first few weeks of treatment and resolved within a few weeks after treatment was discontinued. These cases are thought to be almost entirely due to the development of the syndrome of inappropriate secretion of antidiuretic hormone, preventing the reabsorption of water and sodium ions in the distal tubule of the kidney precipitated by selective serotonin reuptake inhibitors. ${ }^{58} 59$

\section{Other outcomes}

Other outcomes for which some evidence of an association with antidepressant use exists include all cause mortality, ${ }^{6061}$ seizures, ${ }^{62}$ road traffic accidents, ${ }^{63}$ and adverse drug reactions,${ }^{65}$ 
but results are not consistent and evidence in older people with which to compare our findings is lacking.

\section{Clinical implications and future research}

Some of our findings are unexpected-in particular, that contrary to expectations tricyclic antidepressants seem to be the safest class of antidepressant in older people for the adverse outcomes considered in this study. Tricyclic antidepressants were prescribed at lower doses than the other drugs, but some evidence shows that low dose tricyclic antidepressants are similar to higher dose tricyclics in reducing symptoms of depression. ${ }^{720}$ Little evidence exists as to whether low dose tricyclic antidepressants are as efficacious as selective serotonin reuptake inhibitors at higher doses in the treatment of depression; in addition, tricyclic antidepressants may be associated with higher discontinuation rates owing to side effects such as sedation and dry mouth. ${ }^{6}$ The potential risks and benefits of different antidepressants therefore need careful consideration when these drugs are prescribed to older people.

Further research is needed to confirm our findings. Few randomised trials of antidepressants have been done in older people, in a primary care setting, with sufficient size and length of follow-up to assess adverse outcomes as well as benefits, so a long term randomised trial of antidepressants in older people with depression in primary care is needed to compare benefits and risks of more common adverse events between a selective serotonin reuptake inhibitor and a low dose tricyclic antidepressant. Research is also needed to confirm our findings with other data sources of older people in a community setting and to assess any risks associated with switching between antidepressant drugs. If our findings are confirmed in other studies, this would have implications for the selection of antidepressant treatment in older people, who are already at higher risk of many of these adverse outcomes.

\section{Conclusions}

This study has found that selective serotonin reuptake inhibitors and drugs in the group of other antidepressants were associated with an increased risk of several adverse outcomes compared with tricyclic antidepressants. Among the most commonly prescribed individual drugs, trazodone, mirtazapine, and venlafaxine were associated with the highest rates for some outcomes. As this is an observational study, it is susceptible to confounding by indication, channelling bias, and residual confounding. Other differences in characteristics may exist between patients prescribed different antidepressant drugs, which we have not adjusted for and which may account for some of the associations between the drugs and the adverse outcomes. Further research is needed to confirm these findings.

We thank the practices and patients who provide data to QResearch. This project was funded by the NIHR Health Technology Assessment Programme (project number 06/42/01) and will be published in full in Health Technology Assessment. Further information about the project is available on the HTA programme website (www.hta.ac.uk/).

Contributors: CC was involved in the conception and design of the study, analysing and interpreting data, and reviewing the literature; she wrote the draft manuscript. PD was involved in the design of the study, statistical analysis, interpreting data, and reviewing the literature. RM and $A A$ were involved in the conception and design of the study, interpretation of data, and reviewing the literature. GB was involved in interpretation of data and reviewing the literature. $\mathrm{JH}-\mathrm{C}$ was involved in the conception and design of the study, extracted the data, and was involved in interpretation of data and reviewing the literature. All authors critically reviewed the paper. $\mathrm{CC}$ is the guarantor.

Funding: This project was funded by the NIHR Health Technology Assessment Programme (project number 06/42/01). The views and opinions expressed are those of the authors and do not necessarily reflect those of the Department of Health.

Competing interests: All authors have completed the Unified Competing Interest form at www.icmje.org/coi_disclosure.pdf (available on request from the corresponding author) and declare: all authors had financial support from the NIHR Health Technology Assessment Programme (project number 06/42/01) for the submitted work; no financial relationships with any organisations that might have an interest in the submitted work in the previous three years; $\mathrm{JH}-\mathrm{C}$ is director of QResearch, which is a not for profit venture between the University of Nottingham and EMIS (commercial supplier of general practice clinical computer systems), and director of ClinRisk Ltd (medical software company); RM has received financial support for speaking at meetings sponsored by several pharmaceutical companies about the non-drug treatment of depression and bipolar disorder; no other relationships or activities that could appear to have influenced the submitted work.

Ethical approval: The project was independently peer reviewed by the QResearch Scientific Board and has been reported to Trent Research Ethics Committee in accordance with the agreed procedure.

Data sharing: The patient level data from the QResearch databases are specifically licensed according to the governance framework. See www.qresearch.org for further details.

1 McDougall FA, Matthews FE, Kvaal K, Dewey ME, Brayne C. Prevalence and symptomatology of depression in older people living in institutions in England and Wales. Age Ageing 2007;36:562-8

2 Beekman AT, Copeland JR, Prince MJ. Review of community prevalence of depression in later life. Br J Psychiatry 1999:174:307-11.

3 The NHS Information Centre Prescribing Support Unit. Prescriptions dispensed in the community, statistics for 1999 to 2009: England. The Health and Social Care Information Centre, 2010

4 The NHS Information Centre Prescribing Support Unit. Prescription cost analysis: England 2009. The Health and Social Care Information Centre, 2010.

5 The NHS Information Centre Prescribing Support Unit. Prescription cost analysis: England 2004. The Health and Social Care Information Centre, 2005.

6 Mottram P, Wilson K, Strobl J. Antidepressants for depressed elderly. Cochrane Database Syst Rev 2006;1:CD003491.

7 National Institute for Health and Clinical Excellence. Depression: the treatment and management of depression in adults (update). NICE, 2009. (National Clinical Practice Guideline 90.)

8 Cadieux RJ. Antidepressant drug interactions in the elderly: understanding the P-450 system is half the battle in reducing risks. Postgrad Med 1999;106:231-2.

9 Giron MS, Fastbom J, Winblad B. Clinical trials of potential antidepressants: to what exten are the elderly represented? A review. Int J Geriatr Psychiatry 2005;20:201-17.

10 Pollock BG. Adverse reactions of antidepressants in elderly patients. J Clin Psychiatry 1999;60(suppl 20):4-8.

11 Parikh C. Antidepressants in the elderly: challenges for study design and their interpretation. Br J Clin Pharmacol 2000;49:539-47.

12 Reid S, Barbui C. Long term treatment of depression with selective serotonin reuptake inhibitors and newer antidepressants. BMJ 2010;340:c1468

13 Coupland C, Dhiman P, Barton G, Morriss R, Arthur A, Sach T, et al. A study of the safety and harms of antidepressant drugs for older people: a cohort study analysis using a large primary care database. Health Technol Assess 2011 (forthcoming).

14 Hippisley-Cox J, Vinogradova Y, Coupland C, Pringle M. Comparison of key practice characteristics between general practices in England and Wales and general practices in the QRESEARCH database: report to the Health and Social Care Information Centre. University of Nottingham, 2005.

15 Hippisley-Cox J, Pringle M, Hammersley V, Crown N, Wynn A, Meal A, et al. Antidepressants as risk factor for ischaemic heart disease: case-control study in primary care. BMJ 2001:323:666-9.

16 Martinez C, Rietbrock S, Wise L, Ashby D, Chick J, Moseley J, et al. Antidepressant treatment and the risk of fatal and non-fatal self harm in first episode depression: nested case-control study. BMJ 2005;330:389.

17 British Medical Association, Royal Pharmaceutical Society of Great Britain. British national formulary. BMA, RPS, 2007. (No 54.)

18 Townsend $\mathrm{P}$, Phillimore $\mathrm{P}$, Beattie $\mathrm{A}$. Health and deprivation: inequality and the north Croom Helm, 1988

19 Altman DG, Andersen PK. Calculating the number needed to treat for trials where the outcome is time to an event. BMJ 1999;319:1492-95.

20 Furukawa TA, McGuire H, Barbui C. Low dosage tricyclic antidepressants for depression Cochrane Database Syst Rev 2003;3:CD003197.

21 Cassano P, Fava M. Depression and public health: an overview. J Psychosom Res 2002;53:849-57.

22 Nicholson A, Kuper H, Hemingway H. Depression as an aetiologic and prognostic factor in coronary heart disease: a meta-analysis of 6362 events among 146538 participants in 54 observational studies. Eur Heart J 2006;27:2763-74.

23 Hippisley-Cox J, Fielding K, Pringle M. Depression as a risk factor for ischaemic heart disease in men: population based case-control study. BMJ 1998;316:1714-9. 


\section{What is already known on this topic}

Depression is common in older people, and antidepressants including selective serotonin reuptake inhibitors (SSRIs), tricyclic and related antidepressants (TCAs), and other antidepressants are extensively used in its treatment

SSRIs are the most widely used antidepressants, and their use is increasing

Comparatively little is known about safety of these drugs in older people

\section{What this study adds}

Significant differences exist between different antidepressant drugs and their associations with several adverse events in people aged 65 and older with depression

No evidence was found that use of SSRIs or drugs in the group of other antidepressants were associated with a reduced risk of any of the adverse outcomes compared with TCAs

However, they may be associated with an increased risk for certain outcomes

24 Hubbard R, Farrington P, Smith C, Smeeth L, Tattersfield A. Exposure to tricyclic and selective serotonin reuptake inhibitor antidepressants and the risk of hip fracture. $A m \mathrm{~J}$ Epidemiol 2003;158:77-84.

25 Whitaker HJ, Farrington CP, Spiessens B, Musonda P. Tutorial in biostatistics: the self-controlled case series method. Stat Med 2006;25:1768-97.

26 Herrett E, Thomas SL, Schoonen WM, Smeeth L, Hall AJ. Validation and validity of diagnoses in the General Practice Research Database: a systematic review. Br J Clin Pharmacol 2010:69:4-14.

27 Khan NF, Harrison SE, Rose PW. Validity of diagnostic coding within the General Practice Research Database: a systematic review. Br J Gen Pract 2010;60:e128-36.

28 Stone M, Laughren T, Jones ML, Levenson M, Holland PC, Hughes A, et al. Risk of suicidality in clinical trials of antidepressants in adults: analysis of proprietary data submitted to US Food and Drug Administration. BMJ 2009;339:b2880.

29 Barbui C, Esposito E, Cipriani A. Selective serotonin reuptake inhibitors and risk of suicide: a systematic review of observational studies. CMAJ 2009;180:291-7.

30 Monster TBM, Johnsen SP, Olsen ML, McLaughlin JK, Sorensen HT. Antidepressants and risk of first-time hospitalization for myocardial infarction: a population-based case-control study. Am J Med 2004;117:732-7.

31 Tata LJ, West J, Smith C, Farrington P, Card T, Smeeth L, et al. General population based study of the impact of tricyclic and selective serotonin reuptake inhibitor antidepressants on the risk of acute myocardial infarction. Heart 2005;91:465-71.

32 Cohen HW, Gibson G, Alderman MH. Excess risk of myocardial infarction in patients treated with antidepressant medications: association with use of tricyclic agents. $A m$ Med 2000;108:2-8.

33 Blanchette CM, Simoni-Wastila L, Zuckerman IH, Stuart B. A secondary analysis of a duration response association between selective serotonin reuptake inhibitor use and the risk of acute myocardial infarction in the aging population. Ann Epidemiol 2008;18:316-21.

34 Sauer WH, Berlin JA, Kimmel SE. Effect of antidepressants and their relative affinity for the serotonin transporter on the risk of myocardial infarction. Circulation 2003;108:32-6.

35 Schlienger RG, Fischer LM, Jick H, Meier CR. Current use of selective serotonin reuptake inhibitors and risk of acute myocardial infarction. Drug Saf 2004;27:1157-65.

36 Tiihonen J, Lonnqvist J, Wahlbeck K, Klaukka T, Tanskanen A, Haukka J. Antidepressants and the risk of suicide, attempted suicide, and overall mortality in a nationwide cohort. Arch Gen Psychiatry 2006;63:1358-67.

37 Smoller JW, Allison M, Cochrane BB, Curb JD, Perlis RH, Robinson JG, et al. Antidepressant use and risk of incident cardiovascular morbidity and mortality among postmenopausal women in the Women's Health Initiative Study. Arch Intern Med 2009;169:2128-39.

38 Trifiro G, Dieleman J, Sen EF, Gambassi G, Sturkenboom M. Risk of ischemic stroke associated with antidepressant drug use in elderly persons. J Clin Psychopharmacol 2010;30:252-8.

39 Skop B, Brown T. Potential vascular and bleeding complications of treatment with selective serotonin reuptake inhibitors. Psychosomatics 1996;37:12-6.

40 Schlienger RG, Meier CR. Effect of selective serotonin reuptake inhibitors on platelet activation: can they prevent acute myocardial infarction? Am J Cardiovasc Drugs 2003;3:149-62.

41 Darowski A, Chambers SACF, Chambers DJ. Antidepressants and falls in the elderly. Drug Aging 2009;26:381-94

42 Kerse N, Flicker L, Pfaff JJ, Draper B, Lautenschlager NT, Sim M, et al. Falls, depression and antidepressants in later life: a large primary care appraisal. PLOS One 2008:3:e2423.

43 Kallin K, Gustafson Y, Sandman P-O, Karlsson S. Drugs and falls in older people in geriatric care settings. Aging Clin Exp Res 2004;16:270-6.

44 Arfken CL, Wilson JG, Aronson SM. Retrospective review of selective serotonin reuptake inhibitors and falling in older nursing home residents. Int Psychogeriatr 2001;13:85-91.

45 Ziere G, Dieleman JP, van der Cammen TJM, Hofman A, Pols HAP, Stricker BHC. Selective serotonin reuptake inhibiting antidepressants are associated with an increased risk of nonvertebral fractures. J Clin Psychopharmacol 2008:28:411-7.
46 Richards JB, Papaioannou A, Adachi JD, Joseph L, Whitson HE, Prior JC, et al. Effect of selective serotonin reuptake inhibitors on the risk of fracture. Arch Intern Med 2007:167:188-94.

47 Vestergaard P, Rejnmark L, Mosekilde L. Selective serotonin reuptake inhibitors and other antidepressants and risk of fracture. Calcif Tissue Int 2008;82:92-101.

48 Haney EM, Chan BK, Diem SJ, Ensrud KE, Cauley JA, Barrett-Connor E, et al. Association of low bone mineral density with selective serotonin reuptake inhibitor use by older men. Arch Intern Med 2007;167:1246-51.

49 Diem SJ, Blackwell TL, Stone KL, Yaffe K, Cauley JA, Whooley MA, et al. Depressive symptoms and rates of bone loss at the hip in older women. J Am Geriatr SoC 2007;55:824-31.

50 De Abajo FJ, Rodriguez LAG, Montero D. Association between selective serotonin reuptake inhibitors and upper gastrointestinal bleeding: population based case-control study. BMJ 1999;319:1106-9.

51 De Abajo FJ, Garcia-Rodriguez LA. Risk of upper gastrointestinal tract bleeding associated with selective serotonin reuptake inhibitors and venlafaxine therapy: interaction with nonsteroidal anti-inflammatory drugs and effect of acid-suppressing agents. Arch Gen Psychiatry 2008:65:795-803.

52 Van Walraven C, Mamdani MM, Wells PS, Williams JI. Inhibition of serotonin reuptake by antidepressants and upper gastrointestinal bleeding in elderly patients: retrospective cohort study. BMJ 2001;323:655-8.

53 De Abajo FJ, Montero D, García Rodríguez LA, Madurga M. Antidepressants and risk of upper gastrointestinal bleeding. Basic Clin Pharmacol Toxicol 2006;98:304-10.

54 Opatrny L, Delaney JAC, Suissa S. Gastro-intestinal haemorrhage risks of selective serotonin receptor antagonist therapy: a new look. Br J Clin Pharmacol 2008;66:76-81.

55 Spigset $\mathrm{O}$, Hedenmalm K. Hyponatremia in relation to treatment with antidepressants: a survey of reports in the World Health Organization database for spontaneous reporting of adverse drug reactions. Pharmacotherapy 1997;17:348-52.

56 Movig KLL, Leufkens HGM, Lenderink AW, van den Akker VGA, Hodiamont PPG, Goldschmidt HMJ, et al. Association between antidepressant drug use and hyponatraemia: a case-control study. Br J Clin Pharmacol 2002;53:363-9.

57 Kirby D, Harrigan S, Ames D. Hyponatraemia in elderly psychiatric patients treated with selective serotonin reuptake inhibitors and venlafaxine: a retrospective controlled study in an inpatient unit. Int J Geriatr Psychiatry 2002;17:231-7.

58 Jacob S, Spinler SA. Hyponatremia associated with selective serotonin-reuptake inhibitors in older adults. Ann Pharmacother 2006;40:1618-22.

59 Kirby D, Ames D. Hyponatraemia and selective serotonin re-uptake inhibitors in elderly patients. Int J Geriat Psychiatry 2001:16:484-93.

60 Bingefors K, Isacson D, Knorring LV, Smedby B, Wicknertz K. Antidepressant-treated patients in ambulatory care-mortality during a nine-year period after first treatment. $\mathrm{Br}$ J Psychiatry 1996;169:647-54

61 Ryan J, Carriere I, Ritchie K, Stewart R, Toulemonde G, Dartigues J-F, et al. Late-life depression and mortality: influence of gender and antidepressant use. Br J Psychiatry 2008;192:12-8.

62 Rosenstein DL, Nelson JC, Jacobs SC. Seizures associated with antidepressants: a review. J Clin Psychiatry 1993;54:289-99.

63 Ray WA, Fought RL, Decker MD. Psychoactive drugs and the risk of injurious motor vehicle crashes in elderly drivers. Am J Epidemiol 1992;136:873-83.

64 Leveille S, Buchner D, Koepsell T, McCloskey L, Wolf M, Wagner E. Psychoactive medications and injurious motor vehicle collisions involving older drivers. Epidemiology 1994:5:591-8.

65 Vassilev ZP, Chu AF, Ruck B, Adams EH, Marcus SM. Evaluation of adverse drug reactions reported to a poison control center between 2000 and 2007. Am J Health Syst Pharm 2009;66:481-7.

Accepted: 13 June 2011

Cite this as: BMJ 2011;343:d4551 


\section{Tables}

Table 1/ Characteristics of study cohort at baseline. Values are numbers (percentages) unless stated otherwise

\begin{tabular}{|c|c|}
\hline Characteristic & Study cohort $(n=60746)$ \\
\hline Female sex & $40516(66.7)$ \\
\hline \multicolumn{2}{|l|}{ Age group (years): } \\
\hline $65-74$ & $31341(51.6)$ \\
\hline $75-84$ & $21497(35.4)$ \\
\hline$\geq 85$ & $7908(13.0)$ \\
\hline Mean (SD) age (years) & $75.0(7.6)$ \\
\hline \multicolumn{2}{|l|}{ Severity of depression (index diagnosis): } \\
\hline Mild & $42281(69.6)$ \\
\hline Moderate & $15639(25.7)$ \\
\hline Severe & $2826(4.7)$ \\
\hline Recorded history of depression before age 65 & $8943(14.7)$ \\
\hline \multicolumn{2}{|l|}{ Smoking status: } \\
\hline Non-smoker & $33656(55.4)$ \\
\hline Ex-smoker & $13005(21.4)$ \\
\hline Smoker & $10989(18.1)$ \\
\hline Not recorded & $3096(5.1)$ \\
\hline Townsend deprivation score: & $(n=59003)$ \\
\hline Lowest fifth & $12840(21.8)$ \\
\hline Second fifth & $11681(19.8)$ \\
\hline Third fifth & $12264(20.8)$ \\
\hline Fourth fifth & $12315(20.9)$ \\
\hline Highest fifth & $9903(16.8)$ \\
\hline \multicolumn{2}{|l|}{ Comorbidities } \\
\hline Coronary heart disease & $11981(19.7)$ \\
\hline Diabetes & $6169(10.2)$ \\
\hline Hypertension & $23654(38.9)$ \\
\hline Stroke/transient ischaemic attack & $6448(10.6)$ \\
\hline Any cancer & $5032(8.3)$ \\
\hline Dementia & $1091(1.8)$ \\
\hline Epilepsy/seizures & $953(1.6)$ \\
\hline Parkinson's disease & $869(1.4)$ \\
\hline Hypothyroidism & $3956(6.5)$ \\
\hline Obsessive-compulsive disorder & $119(0.2)$ \\
\hline Previous falls & $4979(8.2)$ \\
\hline \multicolumn{2}{|l|}{ Drugs at baseline } \\
\hline Anticonvulsants & $1671(2.8)$ \\
\hline Antihypertensive drugs & $30363(50.0)$ \\
\hline Antipsychotics & $5332(8.8)$ \\
\hline Aspirin & $17863(29.4)$ \\
\hline Hypnotics/anxiolytics & $14391(23.7)$ \\
\hline Lithium & $148(0.2)$ \\
\hline Non-steroidal anti-inflammatory drugs & $34618(57.0)$ \\
\hline Statins & $10283(16.9)$ \\
\hline
\end{tabular}


Table 2| Doses prescribed by antidepressant class in defined daily doses ${ }^{*}$. Values are numbers of prescriptions (column percentages)

\begin{tabular}{lccc} 
Defined daily dose (DDD) & \multicolumn{3}{c}{ Antidepressant class } \\
\cline { 2 - 4 } prescribed & Tricyclic antidepressants & Selective serotonin reuptake inhibitors & Other \\
$\leq 0.5$ DDD & $250208(70.0)$ & $96870(13.8)$ & $27912(19.2)$ \\
\hline$>0.5 / \leq 1$ DDD & $75922(21.2)$ & $505093(72.0)$ & $77286(53.2)$ \\
\hline$>1 / \leq 1.5$ DDD & $26139(7.3)$ & $25037(3.6)$ & $33511(23.1)$ \\
\hline$>1.5$ DDD & $5308(1.5)$ & $75021(10.7)$ & $6664(4.6)$ \\
\hline Total & 357577 & 702021 & 145373 \\
\hline
\end{tabular}

*Dose prescribed could not be calculated for all prescriptions issued during study period either because dosing directions were not recorded or insufficient detail was recorded or, for certain drugs, DDD value was not available; doses were combined when patients received more than one prescription with different doses for same drug on same day. 
Table 3| Hazard ratios for six adverse outcomes (all cause mortality, attempted suicide/self harm, myocardial infarction, stroke/transient ischaemic attack, falls, and fractures) by antidepressant class, unadjusted and adjusted for confounders

\begin{tabular}{|c|c|c|c|}
\hline \multirow[b]{2}{*}{ Antidepressant class } & \multirow[b]{2}{*}{ No of events* } & \multicolumn{2}{|c|}{ Hazard ratio $(95 \% \mathrm{Cl})$} \\
\hline & & Unadjusted & Adjusted $†$ \\
\hline \multicolumn{4}{|l|}{ All cause mortality } \\
\hline Not taking antidepressants & 8210 & 1.00 & 1.00 \\
\hline Tricyclic antidepressants & 2337 & 0.99 (0.95 to 1.04$)$ & $1.16(1.10$ to 1.22$)$ \\
\hline Selective serotonin reuptake inhibitors & 5782 & $1.61(1.55$ to 1.66$)$ & 1.54 (1.48 to 1.59$)$ \\
\hline Other antidepressants & 1268 & 1.77 (1.66 to 1.87$)$ & 1.66 (1.56 to 1.77$)$ \\
\hline Total events/total patients & $17597 / 60640$ & & \\
\hline \multicolumn{4}{|l|}{ Attempted suicide/self harm } \\
\hline Not taking antidepressants & 150 & 1.00 & 1.00 \\
\hline Tricyclic antidepressants & 89 & $1.67(1.27$ to 2.18$)$ & 1.70 (1.28 to 2.25$)$ \\
\hline Selective serotonin reuptake inhibitors & 178 & $2.22(1.77$ to 2.78$)$ & 2.16 ( 1.71 to 2.71$)$ \\
\hline Other antidepressants & 79 & 5.80 (4.41 to 7.63$)$ & 5.16 (3.90 to 6.83$)$ \\
\hline Total events/total patients & $496 / 59536$ & & \\
\hline \multicolumn{4}{|l|}{ Myocardial infarction } \\
\hline Not taking antidepressants & 1264 & 1.00 & 1.00 \\
\hline Tricyclic antidepressants & 362 & $1.02(0.91$ to 1.15$)$ & 1.09 (0.96 to 1.23$)$ \\
\hline Selective serotonin reuptake inhibitors & 614 & $1.16(1.05$ to 1.27$)$ & 1.15 (1.04 to 1.27$)$ \\
\hline Other antidepressants & 110 & $1.01(0.83$ to 1.23$)$ & 1.04 (0.85 to 1.27$)$ \\
\hline Total events/total patients & $2350 / 56428$ & & \\
\hline \multicolumn{4}{|l|}{ Stroke/transient ischaemic attack } \\
\hline Not taking antidepressants & 2811 & 1.00 & 1.00 \\
\hline Tricyclic antidepressants & 791 & $1.01(0.93$ to 1.10$)$ & $1.02(0.93$ to 1.11$)$ \\
\hline Selective serotonin reuptake inhibitors & 1384 & $1.19(1.12$ to 1.27$)$ & 1.17 (1.10 to 1.26$)$ \\
\hline Other antidepressants & 317 & 1.35 (1.21 to 1.52$)$ & 1.37 (1.22 to 1.55$)$ \\
\hline Total events/total patients & $5303 / 54198$ & & \\
\hline \multicolumn{4}{|l|}{ Falls } \\
\hline Not taking antidepressants & 5208 & 1.00 & 1.00 \\
\hline Tricyclic antidepressants & 1704 & $1.20(1.14$ to 1.27$)$ & $1.30(1.23$ to 1.38$)$ \\
\hline Selective serotonin reuptake inhibitors & 3575 & $1.71(1.64$ to 1.79$)$ & 1.66 (1.58 to 1.73$)$ \\
\hline Other antidepressants & 631 & 1.45 (1.34 to 1.58$)$ & 1.39 (1.28 to 1.52$)$ \\
\hline Total events/total patients & $11118 / 55669$ & & \\
\hline \multicolumn{4}{|l|}{ Fracture } \\
\hline Not taking antidepressants & 2507 & 1.00 & 1.00 \\
\hline Tricyclic antidepressants & 809 & $1.23(1.13$ to 1.33$)$ & 1.26 (1.16 to 1.37$)$ \\
\hline Selective serotonin reuptake inhibitors & 1597 & 1.61 (1.51 to 1.72$)$ & 1.58 (1.48 to 1.68$)$ \\
\hline Other antidepressants & 341 & 1.64 (1.46 to 1.84$)$ & 1.64 (1.46 to 1.84$)$ \\
\hline Total events/total patients & $5254 / 52814$ & & \\
\hline
\end{tabular}

\section{${ }^{*}$ Based on numbers included in unadjusted analyses.}

†Adjusted for sex, age (five year bands), year, severity of depression, depression before age 65 , smoking status, Townsend deprivation score, coronary heart disease, diabetes, hypertension, cancer, dementia, Parkinson's disease, hypothyroidism, obsessive-compulsive disorder, epilepsy/seizures, statins, non-steroidal anti-inflammatory drugs, antipsychotics, lithium, aspirin, antihypertensive drugs, anticonvulsant drugs, and hypnotics/anxiolytics; all outcomes except stroke/transient ischaemic attack also adjusted for stroke/transient ischaemic attack at baseline; fracture outcome also adjusted for falls at baseline. 
Table 4| Hazard ratios for five adverse outcomes (upper gastrointestinal bleeding, epilepsy/seizures, road traffic accidents, adverse drug reactions, and hyponatraemia) by antidepressant class, unadjusted and adjusted for confounders

\begin{tabular}{|c|c|c|c|}
\hline \multirow[b]{2}{*}{ Antidepressant class } & \multirow[b]{2}{*}{ No of events* } & \multicolumn{2}{|c|}{ Hazard ratio $(95 \% \mathrm{Cl})$} \\
\hline & & Unadjusted & Adjusted $†$ \\
\hline \multicolumn{4}{|l|}{ Upper gastrointestinal bleeding } \\
\hline Not taking antidepressants & 671 & 1.00 & 1.00 \\
\hline Tricyclic antidepressants & 229 & $1.21(1.04$ to 1.41$)$ & $1.29(1.10$ to 1.51$)$ \\
\hline Selective serotonin reuptake inhibitors & 365 & 1.27 (1.11 to 1.44$)$ & $1.22(1.07$ to 1.40$)$ \\
\hline Other antidepressants & 79 & 1.36 (1.08 to 1.72$)$ & 1.37 (1.08 to 1.74$)$ \\
\hline Total events/total patients & $1344 / 59389$ & & \\
\hline \multicolumn{4}{|l|}{ Epilepsy/seizures } \\
\hline Not taking antidepressants & 223 & 1.00 & 1.00 \\
\hline Tricyclic antidepressants & 58 & 0.99 (0.74 to 1.32$)$ & $1.02(0.76$ to 1.38$)$ \\
\hline Selective serotonin reuptake inhibitors & 177 & 1.98 (1.62 to 2.43$)$ & $1.83(1.49$ to 2.26$)$ \\
\hline Other antidepressants & 39 & $2.32(1.67$ to 3.24$)$ & $2.24(1.60$ to 3.15$)$ \\
\hline Total events/total patients in analysis & $497 / 59691$ & & \\
\hline \multicolumn{4}{|l|}{ Road traffic accidents } \\
\hline Not taking antidepressants & 252 & 1.00 & 1.00 \\
\hline Tricyclic antidepressants & 56 & 0.83 (0.62 to 1.11$)$ & $0.86(0.64$ to 1.15$)$ \\
\hline Selective serotonin reuptake inhibitors & 96 & $0.92(0.72$ to 1.16$)$ & $0.89(0.70$ to 1.13$)$ \\
\hline Other antidepressants & 15 & $0.71(0.42$ to 1.19$)$ & $0.67(0.39$ to 1.14$)$ \\
\hline Total events/total patients & $419 / 59678$ & & \\
\hline \multicolumn{4}{|l|}{ Adverse drug reactions } \\
\hline Not taking antidepressants & 417 & 1.00 & 1.00 \\
\hline Tricyclic antidepressants & 139 & 1.09 (0.89 to 1.32$)$ & $1.06(0.86$ to 1.29$)$ \\
\hline Selective serotonin reuptake inhibitors & 231 & 1.20 (1.02 to 1.42$)$ & $1.16(0.98$ to 1.37$)$ \\
\hline Other antidepressants & 37 & $1.00(0.71$ to 1.40$)$ & 0.95 (0.68 to 1.34$)$ \\
\hline Total events/total patients & $824 / 60170$ & & \\
\hline \multicolumn{4}{|l|}{ Hyponatraemia } \\
\hline Not taking antidepressants & 503 & 1.00 & 1.00 \\
\hline Tricyclic antidepressants & 155 & 0.99 (0.82 to 1.18$)$ & $1.05(0.87$ to 1.27$)$ \\
\hline Selective serotonin reuptake inhibitors & 383 & $1.62(1.42$ to 1.86$)$ & $1.52(1.33$ to 1.75$)$ \\
\hline Other antidepressants & 62 & $1.38(1.06$ to 1.80$)$ & $1.28(0.98$ to 1.67$)$ \\
\hline Total events/total patients & $1103 / 60300$ & & \\
\hline
\end{tabular}

${ }^{*}$ Based on numbers included in unadjusted analyses.

†Adjusted for sex, age (five year bands), year, severity of depression, depression before age 65 , smoking status, Townsend deprivation score, coronary heart disease, stroke/transient ischaemic attack, diabetes, hypertension, cancer, dementia, Parkinson's disease, hypothyroidism, obsessive-compulsive disorder, statins, non-steroidal anti-inflammatory drugs, antipsychotics, lithium, aspirin, antihypertensive drugs, anticonvulsant drugs, hypnotics/anxiolytics; all outcomes except epilepsy/seizures also adjusted for epilepsy/seizures at baseline. 
Table 5| Absolute risks of adverse outcomes over one year by antidepressant class and top 11 most commonly prescribed antidepressant drugs

\begin{tabular}{|c|c|c|c|c|c|c|c|c|c|c|c|}
\hline & \multicolumn{11}{|c|}{ Absolute risks over 1 year (\%) } \\
\hline & $\begin{array}{l}\text { All cause } \\
\text { mortality }\end{array}$ & $\begin{array}{l}\text { Attempted } \\
\text { suicide/self } \\
\text { harm }\end{array}$ & $\begin{array}{l}\text { Myocardial } \\
\text { infarction }\end{array}$ & Stroke/TIA & Falls & Fracture & $\begin{array}{l}\text { Upper GI } \\
\text { bleed }\end{array}$ & Epilepsy/seizures & RTA & $\begin{array}{l}\text { Adverse } \\
\text { drug } \\
\text { reaction }\end{array}$ & Hyponatraemia \\
\hline \multicolumn{12}{|c|}{ Antidepressant class } \\
\hline $\begin{array}{l}\text { Not taking } \\
\text { antidepressants }\end{array}$ & 7.04 & 0.25 & 1.00 & 2.23 & 3.46 & 1.76 & 0.42 & 0.21 & 0.16 & 0.26 & 0.29 \\
\hline $\begin{array}{l}\text { Tricyclic } \\
\text { antidepressants }\end{array}$ & 8.12 & 0.43 & 1.09 & 2.26 & 4.49 & 2.18 & 0.54 & 0.21 & 0.13 & 0.28 & 0.30 \\
\hline $\begin{array}{l}\text { Selective serotonin } \\
\text { reuptake inhibitors }\end{array}$ & 10.61 & 0.55 & 1.15 & 2.61 & 5.67 & 2.74 & 0.51 & 0.38 & 0.14 & 0.30 & 0.44 \\
\hline $\begin{array}{l}\text { Other } \\
\text { antidepressants }\end{array}$ & 11.43 & 1.30 & 1.04 & 3.04 & 4.79 & 2.85 & 0.57 & 0.46 & 0.10 & 0.25 & 0.37 \\
\hline \multicolumn{12}{|c|}{ Tricyclic antidepressants } \\
\hline $\begin{array}{l}\text { Amitriptyline } \\
\text { hydrochloride }\end{array}$ & 7.72 & 0.27 & 1.11 & 2.24 & 4.54 & 2.14 & 0.58 & 0.24 & 0.13 & 0.25 & 0.33 \\
\hline $\begin{array}{l}\text { Dosulepin } \\
\text { hydrochloride }\end{array}$ & 7.26 & 0.48 & 1.07 & 2.12 & 4.28 & 2.15 & 0.51 & 0.10 & 0.08 & 0.23 & 0.24 \\
\hline Lofepramine & 10.43 & 0.66 & 1.18 & 2.79 & 4.61 & 2.56 & 0.51 & 0.28 & 0.18 & 0.55 & 0.27 \\
\hline $\begin{array}{l}\text { Trazodone } \\
\text { hydrochloride }\end{array}$ & 12.44 & 1.20 & 1.04 & 2.45 & 5.32 & 1.70 & 0.75 & 0.30 & 0.24 & 0.27 & 0.43 \\
\hline \multicolumn{12}{|c|}{ Selective serotonin reuptake inhibitors } \\
\hline $\begin{array}{l}\text { Citalopram } \\
\text { hydrobromide }\end{array}$ & 10.69 & 0.68 & 1.11 & 2.71 & 6.01 & 2.83 & 0.56 & 0.37 & 0.16 & 0.29 & 0.47 \\
\hline Escitalopram & 10.06 & 0.47 & 1.32 & 2.70 & 5.70 & 2.26 & 0.45 & 0.36 & 0.15 & 0.29 & 0.59 \\
\hline $\begin{array}{l}\text { Fluoxetine } \\
\text { hydrochloride }\end{array}$ & 11.42 & 0.53 & 1.31 & 2.57 & 5.60 & 2.76 & 0.48 & 0.31 & 0.11 & 0.31 & 0.49 \\
\hline $\begin{array}{l}\text { Paroxetine } \\
\text { hydrochloride }\end{array}$ & 8.68 & 0.29 & 1.11 & 2.39 & 4.97 & 2.56 & 0.48 & 0.42 & 0.14 & 0.24 & 0.30 \\
\hline $\begin{array}{l}\text { Sertraline } \\
\text { hydrochloride }\end{array}$ & 10.20 & 0.53 & 0.89 & 2.70 & 5.57 & 2.80 & 0.44 & 0.55 & 0.14 & 0.42 & 0.29 \\
\hline \multicolumn{12}{|c|}{ Other antidepressants } \\
\hline Mirtazapine & 12.05 & 1.56 & 1.11 & 3.06 & 4.11 & 2.56 & 0.44 & 0.33 & 0.07 & 0.27 & 0.31 \\
\hline $\begin{array}{l}\text { Venlafaxine } \\
\text { hydrochloride }\end{array}$ & 11.40 & 1.17 & 1.05 & 3.34 & 5.74 & 3.26 & 0.72 & 0.61 & 0.11 & 0.23 & 0.44 \\
\hline
\end{tabular}

GI=gastrointestinal; RTA=road traffic accident; TIA=transient ischaemic attack.

*Absolute risks for antidepressant drugs adjusted for confounders listed in table 3 . 


\section{Figures}

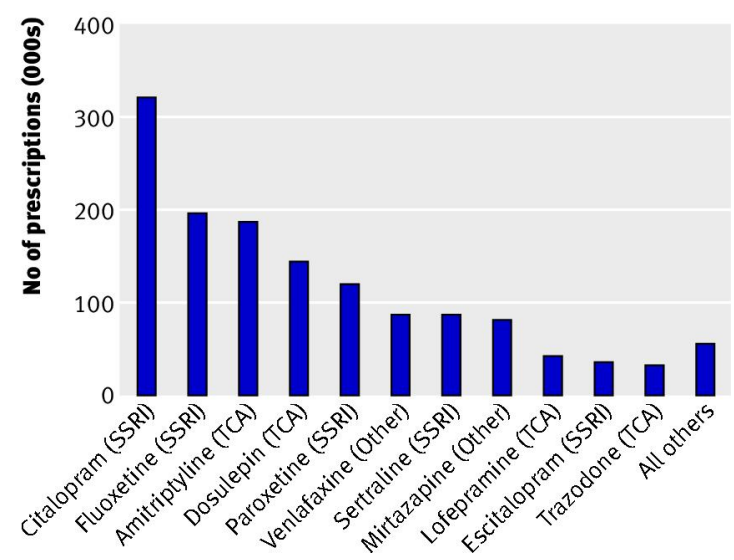

Fig 1 Total number of prescriptions during follow-up for 11 most commonly prescribed antidepressant drugs, in total of 54 038 patients. SSRI=selective serotonin reuptake inhibitor; TCA=tricyclic antidepressant

Amitriptyline (TCA) Dosulepin (TCA) Lofepramine (TCA) Trazodone (TCA) Citalopram (SSRI) Escitalopram (SSRI) Fluoxetine (SSRI) Paroxetine (SSRI) Sertraline (SSRI) Mirtazapine (Other) Venlafaxine (Other)

Amitriptyline (TCA) Dosulepin (TCA) Lofepramine (TCA) Trazodone (TCA) Citalopram (SSRI) Escitalopram (SSRI) Fluoxetine (SSRI) Paroxetine (SSRI) Sertraline (SSRI) Mirtazapine (Other) Venlafaxine (Other)

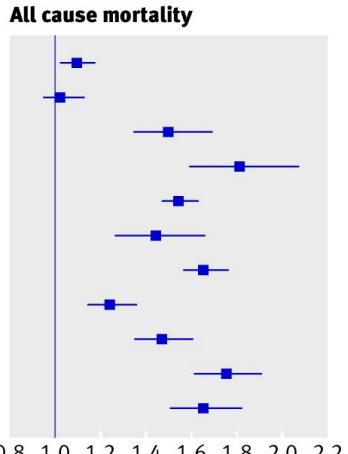

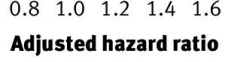

Epilepsy/seizures

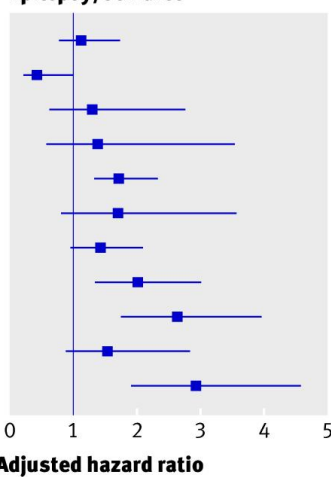

Road traffic accident

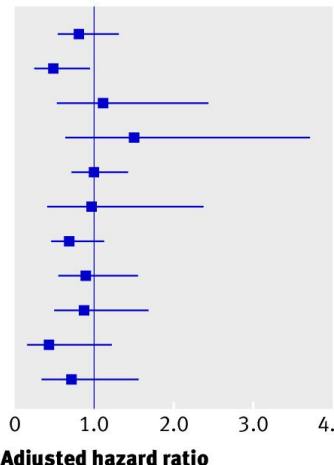

Attempted suicide

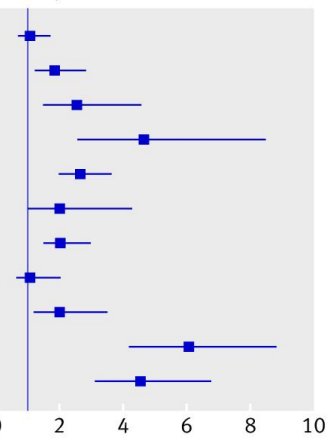

Adjusted hazard ratio

Upper GI bleed

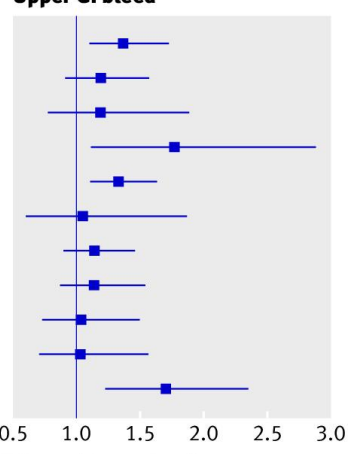

Adjusted hazard ratio

Adverse drug reaction

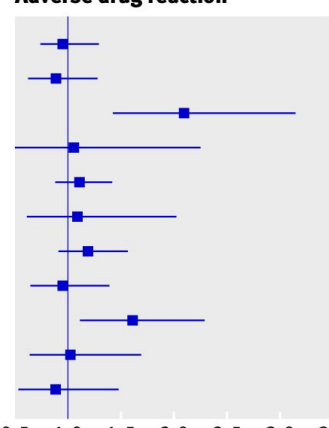

$\begin{array}{llll}0.5 & 1.0 & 1.5 & 2.0 \\ \text { Adjusted hazard ratio }\end{array}$
Myocardial infarction

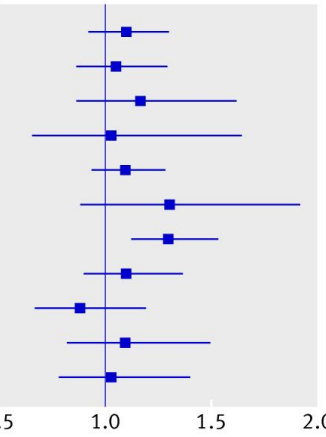

Adjusted hazard ratio

Falls

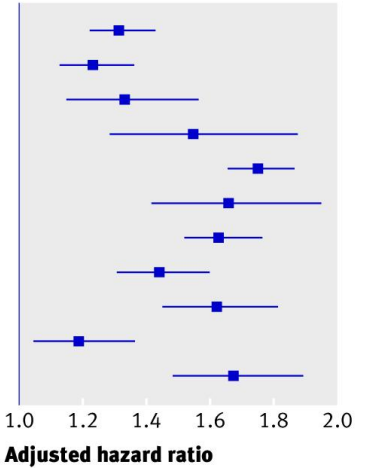

Hyponatraemia

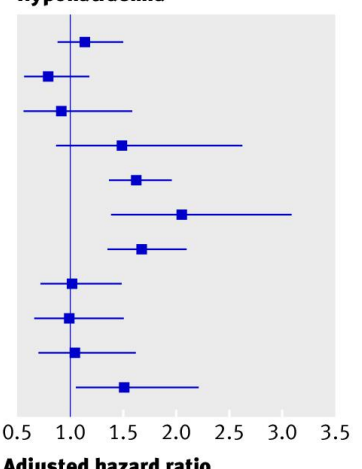

Stroke/TIA

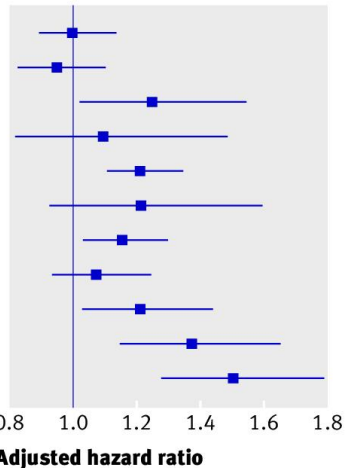

Fracture

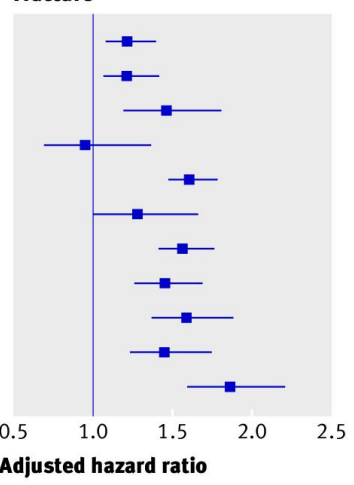


Fig 2 Adjusted (for confounders listed in table 3) hazard ratios (with 95\% Cl) for outcomes according to 11 most commonly prescribed antidepressant drugs. $\mathrm{Gl}=$ gastrointestinal; $\mathrm{SSRI}=$ selective serotonin reuptake inhibitor; TCA=tricyclic antidepressant; $\mathrm{TIA}=$ transient ischaemic attack 